\title{
Article \\ Dual Profile of Environmental Enrichment and Autistic-Like Behaviors in the Maternal Separated Model in Rats
}

\author{
Monireh Mansouri 1,2,3, Hamidreza Pouretemad 1,4, Gregers Wegener 2,5,6 ${ }^{\mathbb{D}}$, Mehrdad $\operatorname{Roghani}^{7}$, \\ Masoud Afshari ${ }^{1}$, Carina Mallard ${ }^{8}$ (D) and Maryam Ardalan ${ }^{2,8, *(D)}$
}

1 Department of Cognitive Psychology, Institute for Cognitive and Brain Sciences, Shahid Beheshti University, Tehran 1983969411, Iran; monirehmansouri@clin.au.dk (M.M.); H-Pouretemad@sbu.ac.ir (H.P.); ma_afshari@sbu.ac.ir (M.A.)

2 Translational Neuropsychiatry Unit, Department of Clinical Medicine, Aarhus University, 8000 Aarhus, Denmark; wegener@clin.au.dk

3 Center of Excellence in Cognitive Neuropsychology, Institute for Cognitive and Brain Sciences, Shahid Beheshti University, Tehran 1983969411, Iran

4 Department of Psychology, Shahid Beheshti University, Tehran 1983969411, Iran

5 Center of Excellence for Pharmaceutical Sciences, North-West University, Potchefstroom 2520, South Africa

6 AUGUST Centre, Department of Clinical Medicine, Aarhus University, 8240 Risskov, Denmark

7 Neurophysiology Research Center, Shahed University, Tehran 3319118651, Iran; mehjour@yahoo.com

8 Centre for Perinatal Medicine and Health, Institute of Neuroscience and Physiology, Sahlgrenska Academy, University of Gothenburg, 50530 Gothenburg, Sweden; carina.mallard@neuro.gu.se

* Correspondence: maryam.ardalan@gu.se or maryamardalan@gmail.com

Citation: Mansouri, M.; Pouretemad, H.; Wegener, G.; Roghani, M.; Afshari, M.; Mallard, C.; Ardalan, M. Dual Profile of Environmental Enrichment and Autistic-Like Behaviors in the Maternal Separated Model in Rats. Int. J. Mol. Sci. 2021, 22, 1173. https://doi.org/10.3390/ijms22031173

Academic Editor: Mercè

Pallas Lliberia

Received: 28 November 2020

Accepted: 14 January 2021

Published: 25 January 202

Publisher's Note: MDPI stays neutral with regard to jurisdictional claims in published maps and institutional affiliations.

Copyright: (C) 2021 by the authors. Licensee MDPI, Basel, Switzerland. This article is an open access article distributed under the terms and conditions of the Creative Commons Attribution (CC BY) license (https:// creativecommons.org/licenses/by/ $4.0 /)$.
Abstract: Background: Environmental Enrichment (EE) has been suggested as a possible therapeutic intervention for neurodevelopmental disorders such as autism. Although the benefits of this therapeutic method have been reported in some animal models and human studies, the unknown pathophysiology of autism as well as number of conflicting results, urge for further examination of the therapeutic potential of EE in autism. Therefore, the aim of this study was to examine the effects of environmental enrichment on autism-related behaviors which were induced in the maternal separation (MS) animal model. Material and Methods: Maternally separated (post-natal day (PND) 1-14, $3 \mathrm{~h}$ /day) and control male rats were at weaning (PND21) age equally divided into rats housed in enriched environment and normal environment. At adolescence (PND42-50), the four groups were behaviorally tested for direct social interaction, sociability, repetitive behaviors, anxiety behavior, and locomotion. Following completion of the behavioral tests, the blood and brain tissue samples were harvested in order to assess plasma level of brain derived neurotrophic factor (BDNF) and structural plasticity of brain using ELISA and stereological methods respectively. Results: We found that environmental enrichment reduced repetitive behaviors but failed to improve the impaired sociability and anxiety behaviors which were induced by maternal separation. Indeed, EE exacerbated anxiety and social behaviors deficits in association with increased plasma BDNF level, larger volume of the hippocampus and infra-limbic region and higher number of neurons in the infra-limbic area $(p<0.05)$. Conclusion: We conclude that environmental enrichment has a significant improvement effect on the repetitive behavior as one of the core autistic-like behaviors induced by maternal separation but has negative effect on the anxiety and social behaviors which might have been modulated by BDNF.

Keywords: animal model of autism; neonatal isolation; environmental enrichment; brain plasticity; BDNF

\section{Introduction}

The effect of environmental factors on brain development has long been known [1]. Poverty or enrichment of the environment, stress, nutrition and many other factors affect structural, cellular and network connections in the brain, and thereby contribute to individuals' future cognitive behaviors and potential psychological disorders [2-5]. 
Autism Spectrum Disorder (ASD) is a neurodevelopmental disorder with a global prevalence of more than $1 \%$ and is characterized by deficits in social and stereotyped behaviors. Despite its prevalence, no definitive treatment has been identified [6]. Autism is commonly recognized as a highly genetic disorder $[7,8]$, but recently, it was found that environmental factors such as early life maternal separation (MS) have significant impact on the risk of autism [9-12]. However, it is not clear to what extent the environmental factors influence the expression of autistic symptoms. Some researchers proposed that one of the reasons for the increase in the prevalence of autism is a change in the lifestyle of families and the high use of digital devices among children from an early age as one of the factors resulting inadequate parent child interaction $[10,13]$. They suggested enrichment of the environment as a potential compensatory factor for the negative effects of such an adverse environmental complication. This non-pharmacological intervention has been used in animal models of neurodevelopmental and neurodegenerative disorders [14], mainly as models of behavioral intervention [15]. The findings pointed to the possibility that adding different objects to the animal's environment through increasing the level of complexity and novelty, enhancement of sensory stimulation, and stimulating cognitive activity and physical training may modify pathophysiological mechanisms, and manifests as an improvement of autistic symptoms [16]. Indeed, preclinical studies showed that rearing in an enriched environment suppressed the expression of some autistic behavioral phenotypes [17-20]. Unfortunately, not all studies are in line with these suggestions, as were observed by lack of recovery and exacerbations of social behavior deficits and anxiety following environmental enrichment (EE) in different studies [21-23].

In our recent study, we observed the beneficial effect of oxytocin on the improvement of autistic-like behaviors with an effect on brain plasticity along with a decrease in plasma BDNF (brain derived neurotrophic factor) levels in a maternal separate rat model of autism [24]. We showed that changes in the plasma BDNF level could be associated with changes in the brain plasticity and improvement in autistic-like symptoms. Accordingly, we decided to investigate the effect of $\mathrm{EE}$ on the mentioned parameters in the current experiment. Therefore, the main purpose of this study was to investigate the effect of environmental enrichment on (i) autistic-like behaviors which were induced by maternal separation, (ii) brain plasticity, and (iii) the plasma BDNF level which is also altered in the ASD patients [25] and also as the main neurotrophic factor involved in brain plasticity.

\section{Results}

\subsection{Repetitive Behaviors}

Repetitive behaviors were assessed using self-grooming and marble burying tests.

\subsubsection{Self-Grooming}

In the open field test, the time spent for self-grooming was recorded as a repetitive behavior. Results of two-way ANOVA analysis showed that there was a significant interaction between MS and EE on the time spent for self-grooming $\left(F_{(1.24)}=18.32, p<0.001\right)$ with significant main effects of MS and EE $\left(F_{(1.24)}=29.28, p<0.001\right.$ and $F_{(1.24)}=14.91$, $p=0.001)$, respectively. Moreover, the maternal separation group spent significantly more time for self-grooming than the other three groups $(p<0.001)$. There was no significant difference between the other groups $(p>0.05)$ (Figure 1A).

\subsubsection{Marble Burying}

There was a significant interaction between the effects of MS and EE $\left(F_{(1.24)}=44.76\right.$, $p<0.001)$ on the burying of marbles. Simple main effects of MS and EE were significant $\left(F_{(1.24)}=32.04, p<0.001\right.$ and $\left.F_{(1.24)}=30.40, p<0.001\right)$, respectively. Maternal separated rats significantly buried a greater number of marbles than the other three groups (Figure 1B, $p<0.001)$. Indeed, the above results showed an increased repetitive behavior in maternal separated rats which were significantly improved by environmental enrichment. 

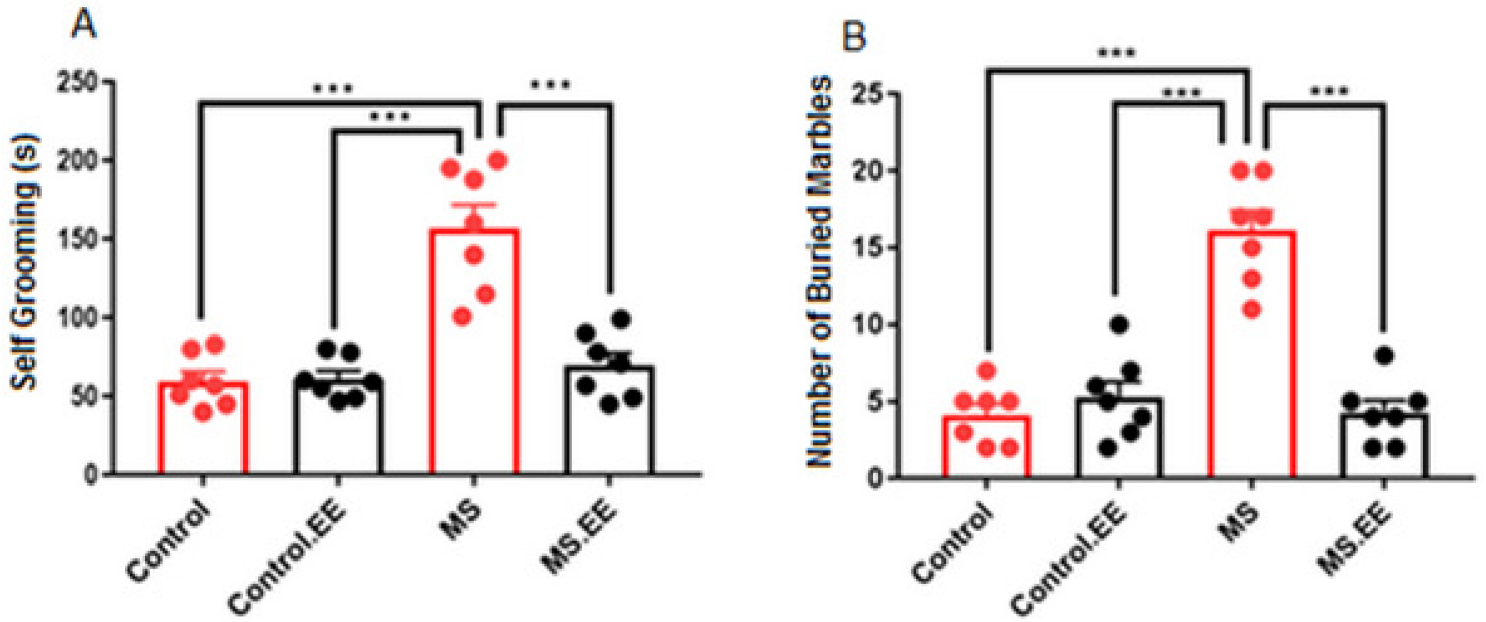

Figure 1. Effects of maternal separation and EE on the stereotypic behaviors. (A): self-grooming, (B): marble burying. ${ }^{* * *} p<0.001 . N=10$ in each group. Data are presented before log-transformation, MS: Maternal Separation, EE: Environmental Enrichment.

\subsection{Social Behavior}

In the three-chamber test, two social behaviors including sociability and direct social interaction were examined.

\subsubsection{Sociability}

Comparison of the time spent in stranger rat chamber with non-social object chamber in this test was used as a sociability index (SI). Within group comparisons showed that in the control group, the time spent in the stranger rat chamber was significantly longer than in the non-social object chamber $(p=0.003)$. While in the MS group, the time spent in the stranger rat chamber was significantly less than in the non-social object chamber $(p=0.005)$. There was no significant improvement in the social behavior in the MS.EE group as the time spent in the non-social object chamber was significantly longer than in the stranger rat chamber $(p=0.001)$. Interestingly, in the control group with enriched environment, sociability was significantly reduced, and the time spent in the non-social object chamber was significantly longer than in the stranger rat chamber $(p=0.035)$ (Figure 2A).
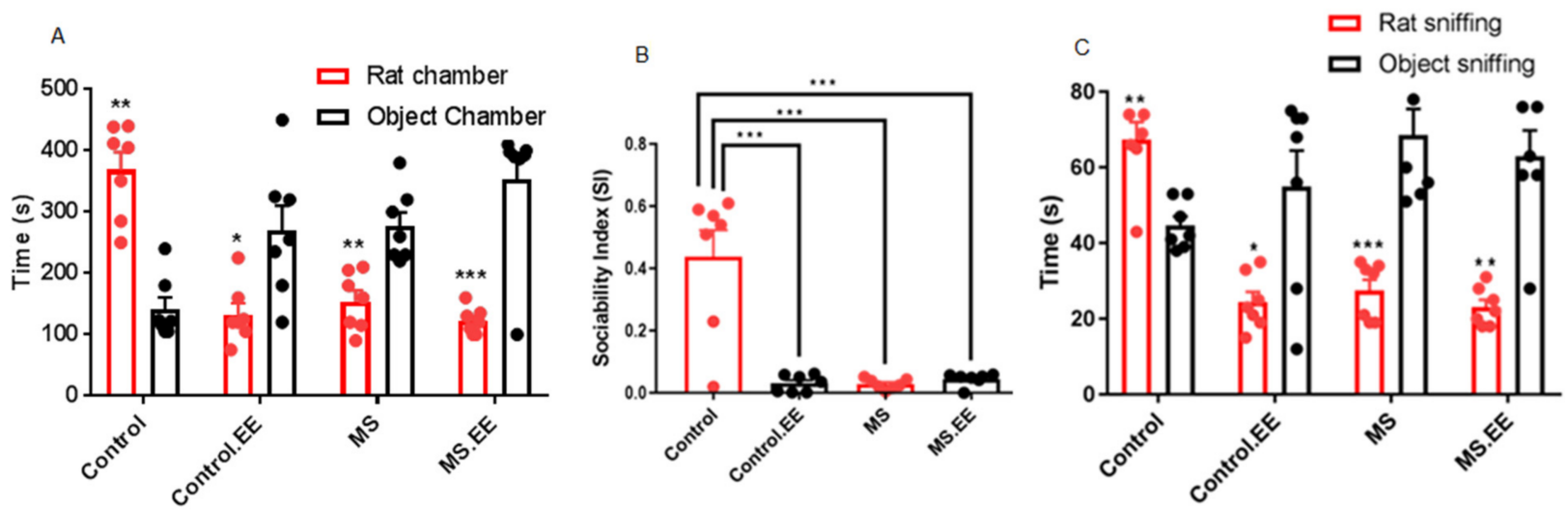

Figure 2. Effects of maternal separation and EE on social behavior (A), sociability index (B) and direct social interaction (C). ${ }^{*} p<0.05,{ }^{* *} p<0.01,{ }^{* * *} p<0.001 . N=10$ in each group. MS: Maternal Separation, EE: Environmental Enrichment.

Social index calculation (time exploring social chamber-time exploring non-social chamber)/(time exploring social chamber + time exploring non-social chamber) confirmed the above result. Two way ANOVA analysis showed that MS and EE had significant main 
effects on the social index $\left(F_{(1,24)}=26.53, p<0.001\right.$ and $\left.F_{(1,24)}=28.57, p<0.001\right)$. Tukey post hoc test showed significant decrease in the SI index in the control.EE, MS, and MS.EE groups in comparison with control group $(p<0.001)$ (Figure 2B).

\subsubsection{Direct Social Interaction}

Durations of direct sniffing of testing rat with stranger rat and with empty cage were recorded as a direct social interaction behavior. The results showed that in the control group, time spent sniffing stranger rat was significantly higher $(p=0.002)$, but in the control.EE, MS, and MS.EE groups, the time spent sniffing stranger rat was significantly lower than sniffing the empty cage ( $p=0.024, p=0.001, p=0.002$, respectively) (Figure $2 \mathrm{C}$ ).

\subsubsection{Anxiety-Like Behavior}

The time spent in the central circle of the open-field test box was recorded as a measure of anxiety behavior in rats. Less time spent in the central circle was indicative of an anxiety behavior in rats. Here, we observed a significant interaction between MS and $\mathrm{EE}\left(F_{(1.24)}=48.24, p<0.001\right)$ on the anxiety behavior and significant simple main effects of MS and $\operatorname{EE~}\left(F_{(1.24)}=64.92, p<0.001 ; F_{(1.24)}=46.97, p<0.001\right)$ on the anxiety behavior. All groups of MS, MS.EE, and control.EE were present in the central circle for significantly less time than the control group $(p<0.001)$ (Figure 3).

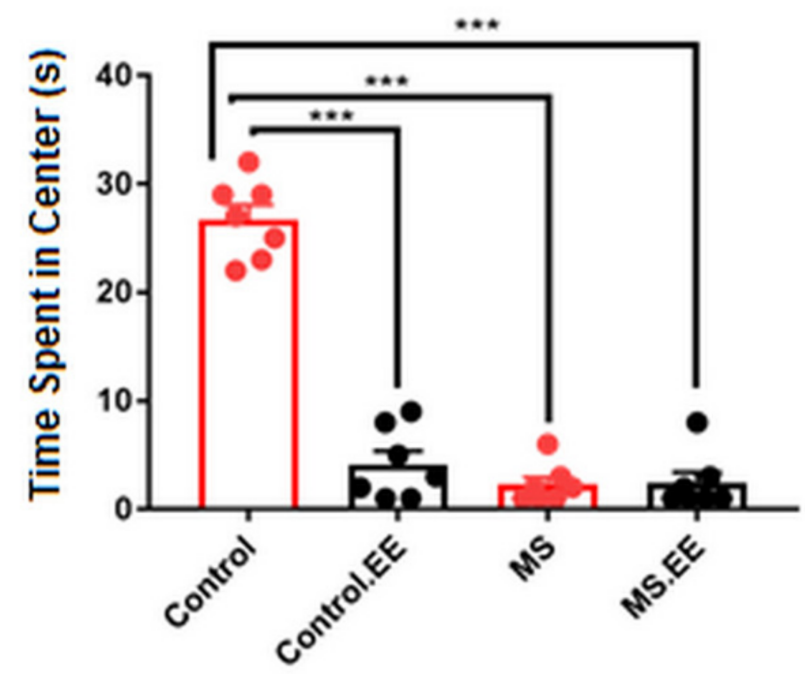

Figure 3. Effects of maternal separation and EE on anxiety behavior in the open field test. ${ }^{* *} p<0.001$. $N=10$ in each group. MS: Maternal Separation, EE: Environmental Enrichment.

\subsection{Motor Behavior}

In the open field test, number of times the lines were crossed by rat were recorded as a locomotion behavior. Data analysis by using two-way ANOVA showed no significant interaction between MS and EE $\left(F_{(1.24)}=0.92, p=0.345\right)$. Accordingly, motor behavior did not significantly change following MS and/or EE (data not shown). 


\section{Plasma BDNF Level}

The results revealed no significant interaction of MS and $\mathrm{EE}\left(F_{(1.20)}=0.02, p=0.88\right)$ but significant main effects of MS $\left(F_{(1.20)}=79.79, p<0.001\right)$ and $\operatorname{EE}\left(F_{(1.20)}=15.60, p=0.001\right)$ on the BDNF plasma level. Tukey post hoc test showed that the plasma level of BDNF was significantly increased in MS, MS.EE, and control.EE groups compared to the control group $(p<0.001, p<0.001, p=0.041)$. MS and MS.EE groups showed also significant differences from control.EE group $(p=0.05, p<0.001)$ but there was no significant difference between MS and MS.EE groups $(p>0.05)$ (Figure 4 ).

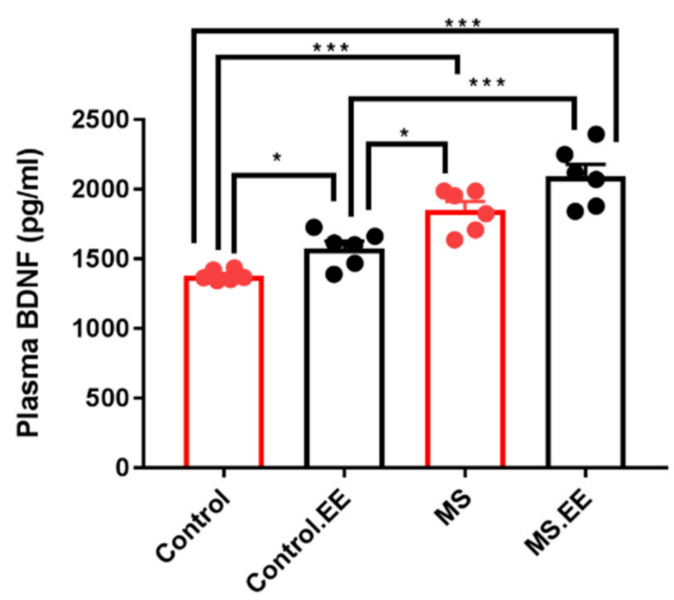

Figure 4. Effects of maternal separation and EE on plasma brain derived neurotrophic factor (BDNF) levels. ${ }^{*} p<0.05,{ }^{* * *} p<0.001 . n=6$ in each group. Data are presented before log-transformation, MS: Maternal Separation, EE: Environmental Enrichment.

\subsection{Quantitative Stereological Measurements}

2.4.1. Effects of MS and EE on the Volume of the Hippocampus and Its Sub-Regions

The results showed significant main effects of MS $\left(F_{(1.20)}=24.12, p<0.001\right)$ and EE $\left(F_{(1.20)}=38.22, p<0.001\right)$ on the total volume of the hippocampus. Regarding subregions of hippocampus, we observed no effects of MS and EE on the volume of GCL and MDG $\left(F_{(1.20)}=3.01, p=0.09\right),\left(F_{(1.20)}=0.456, p=0.50\right),\left(F_{(1.20)}=0.46, p=0.50\right),\left(F_{(1.20)}=0.65\right.$, $p=0.48)$, but significant main effects on the CA1.SR volume $\left(F_{(1.20)}=11.51, p=0.003\right)$ and $\left(F_{(1.20)}=8.54, p=0.008\right)$ were observed. The volume of the hippocampus in the MS, MS.EE, and control.EE groups significantly increased compared to the control group ( $p=0.01$, $p<0.001, p=0.002)$. A significant difference was also found between MS.EE and both MS $(p=0.001)$ and control.EE groups $(p=0.01)$ but no significant change was seen between MS and control.EE $(p>0.05)$ (Figure 5A). The size of CA1.SR area in the MS and MS.EE groups increased significantly in comparison with control group $(p=0.04, p=0.001)$ but there was no significant difference between MS and MS.EE groups ( $p>0.05)$ (Figure 5B). 

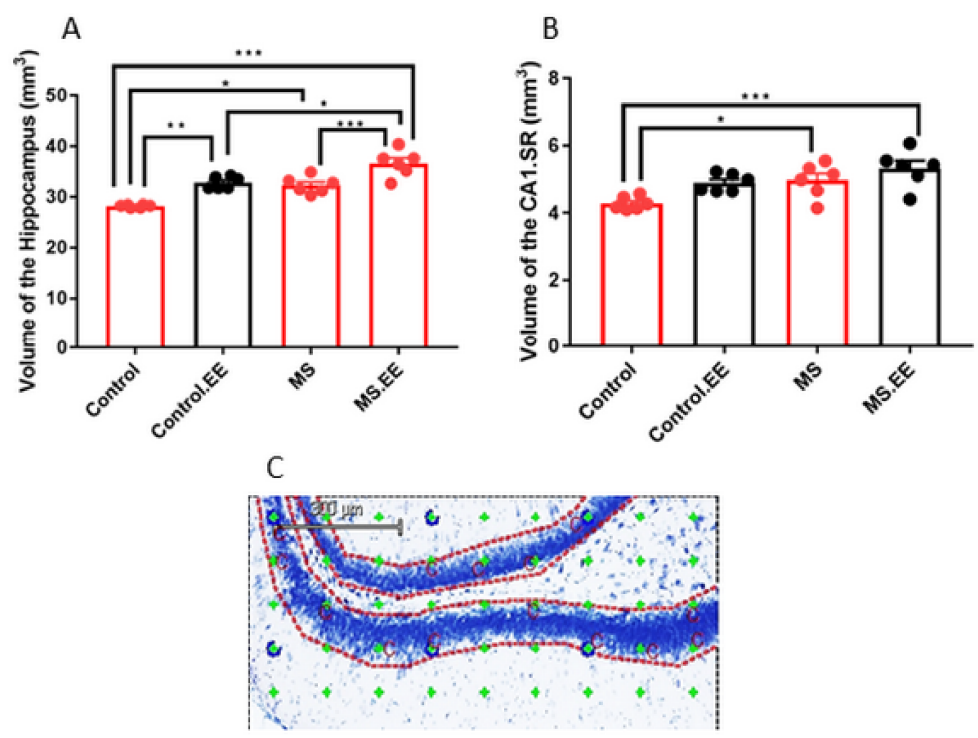

Figure 5. Effects of maternal separation and EE on the hippocampus (A) and CA1.SR volumes (B) ${ }^{*} p<0.05,{ }^{* *} p<0.01,{ }^{* *} p<0.001$. Illustration of Cavalieri estimator using point counting to measure the volume of the GCL sub-region of hippocampus (objective lens $10 \times$ ) (C). $N=6$ in each group. MS: Maternal Separation, EE: Environmental Enrichment.

2.4.2. Effects of MS and EE on the Number of Pyramidal Neurons and Volume of the Infra-Limbic and Pre-Limbic Areas

The result of the volume analysis of the infra-limbic area revealed significant interaction between MS and $\mathrm{EE}\left(F_{(1.20)}=14.54, p=0.001\right)$ with significant main effects of MS $\left(F_{(1.20)}=71.45, p<0.001\right)$ and $\operatorname{EE~}\left(F_{(1.20)}=9.51, p=0.006\right)$. Tukey post hoc analysis showed that the volume of the infra-limbic area in the control.EE, MS, and MS.EE groups was significantly increased in comparison with the control group $(p<0.001)$. There was also a significant difference between MS and control.EE $(p=0.006)$ groups as well as between MS.EE and control.EE groups $(p=0.018)$ (Figure 6A). No significant changes in the volume of the pre-limbic area were detected $(p>0.05)$ (Data were not shown). Regarding changes in the number of pyramidal neurons in the infra-limbic area, there were significant interaction of MS and $\operatorname{EE~}\left(F_{(1.20)}=10.81, p=0.004\right)$ and main effect of $\operatorname{MS}\left(F_{(1.20)}=16.48, p=0.001\right)$ with no significant main effect of $\operatorname{EE~}\left(F_{(1.20)}=2.95, p=0.10\right)$. Neuronal number in the infra-limbic area significantly increased in control.EE $(p=0.01)$, MS $(p<0.001)$, and MS.EE $(p=0.003)$ groups compared to the control group (Figure 6C).

\subsection{Correlations between Behavioral and Biological Parameters}

Two tailed Pearson correlation analysis (Figure 7A,B) showed that sociability index and time spent in the centre of the open field (anxiety behaviour) had significant negative correlations with plasma BDNF level $(r=-0.527, p=0.009$ and $r=-0.570, p=0.001)$. Significant negative correlations between number of pyramidal neurons in the infra-limbic area and social index and time spent in centre of the open field (anxiety behaviour) were also detected $(r=-0.539, p=0.007$ and $r=-0.727, p<0.001)$ (Figure 8A,B). Significant positive correlations between number of neurons in the infra-limbic, self-grooming $(r=0.476, p=0.019)$, and the volume of the infra-limbic were observed $(r=0.664, p<0.001)$ (Figure 8C,D). There was also significant negative correlation between volume of the hippocampus and sociability index $(r=-0.712, p<0.001)$ (Figure 8E). No significant correlations between repetitive behaviours (marble burying and self-grooming) and plasma BDNF level (Figure 7C,D) or hippocampus volume (Figure 8F,G) were observed $(p>0.05)$. Significant positive correlations between plasma BDNF level and number of the neurons in infra-limbic and volume of the hippocampus $(r=0.489, p=0.015$ and $r=0.665, p<0.001)$ were seen (Figure 7E,F). 

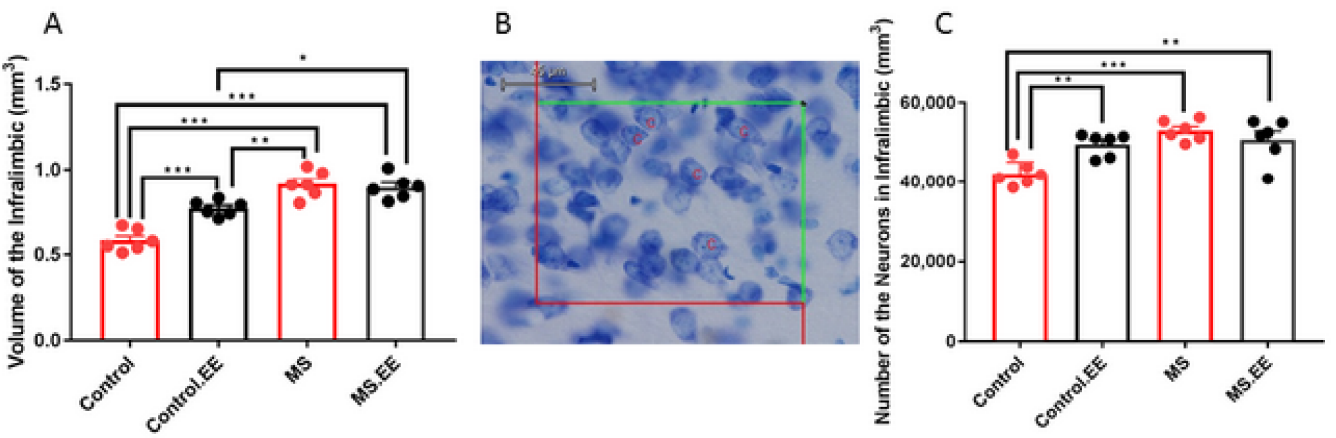

Figure 6. Effects of maternal separation and EE on the (A) volume of infralimbic area. (B) Illustration of counting the number of neurons in the infra-limbic area with optical fractionator method using objective lens $60 \times(\mathrm{C})$ Changes in the number of pyramidal neurons in the infra-limbic area of mPFC following MS and EE. ${ }^{*} p<0.05,{ }^{* *} p<0.01,{ }^{* * *} p<0.001$. $N=6$ in each group. MS: Maternal Separation, EE: Environmental Enrichment.
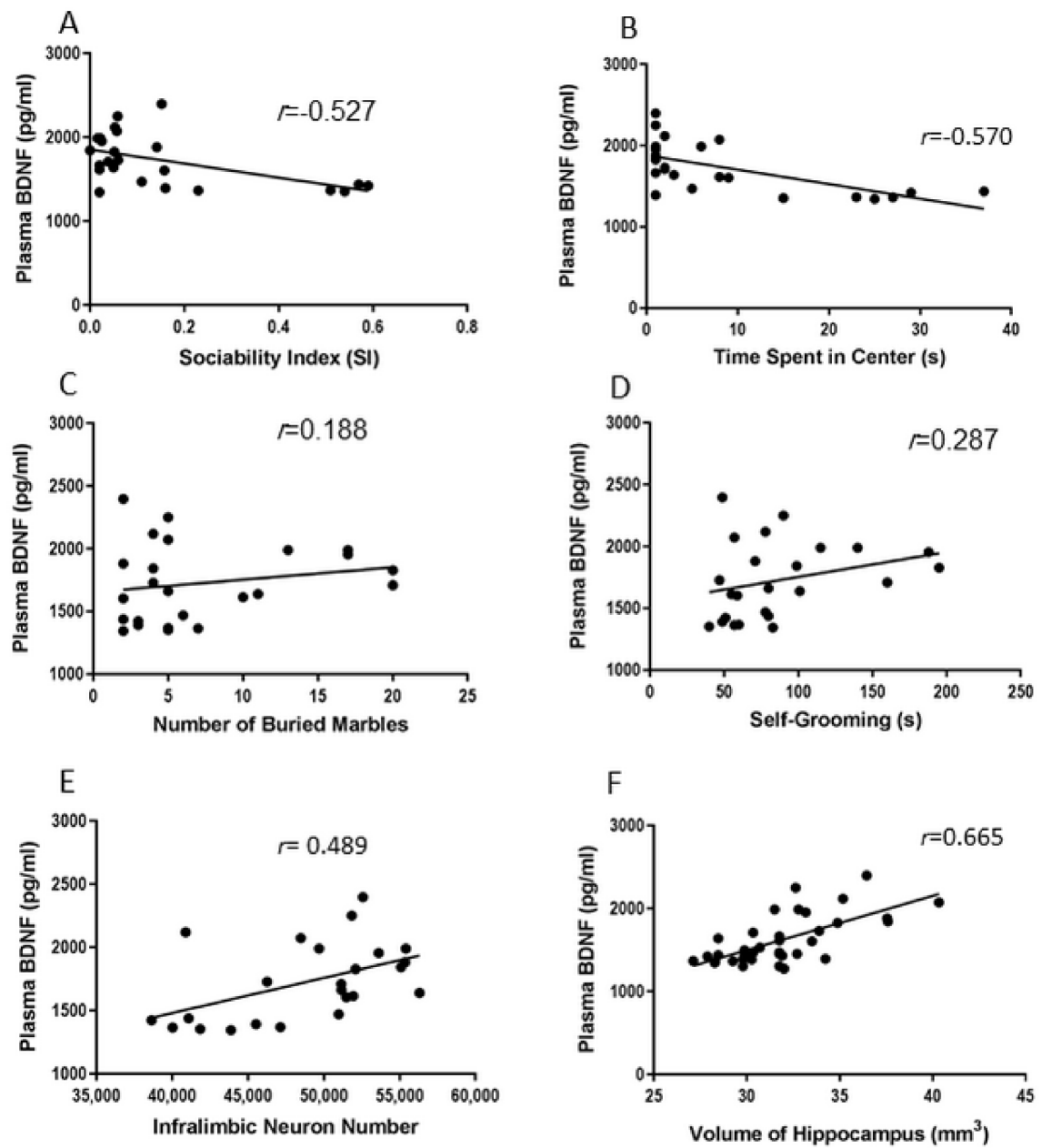

Figure 7. Significant negative correlations between plasma BDNF level and sociability index and time spent in the centre of the open field $(r=-0.527, p=0.009$ and $r=-0.570$, $p=0.001)(\mathbf{A}, \mathbf{B})$. No significant correlation between repetitive behaviours (marble burying and self-grooming) and plasma BDNF level $(\mathbf{C}, \mathbf{D})$ was observed $(p>0.05)$. Significant positive correlations between plasma BDNF level and number of the neurons in infralimbic and volume of the hippocampus $(r=0.489, p=0.015$ and $r=0.665, p<0.001)(\mathbf{E}, \mathbf{F})$. 


\subsection{Results of the Supplementary Experiment (Treatment with both EE and Oxytocin)}

In this section, we tried to investigate the effect of combination of oxytocin and EE on the autistic-like behaviors in connection with changes in brain plasticity in maternal separation and control groups. As was shown in Figure 9, there was a significant difference between control.OE and both control.EE and MS groups in social index $(p<0.001)$, anxiety behavior $(p<0.001)$, and plasma BDNF level $(p<0.05, p<0.001)$. Moreover, there was a significant difference between MS.OE and both MS.EE and MS in social index $p<0.01,(p<0.001)$ and anxiety behavior $(p<0.01, p<0.001)$. A significant difference between MS.OE and MS.EE was observed in the volume of the hippocampus $(p<0.001)$ and plasma BDNF level $(p<0.001)$. Therefore, our results indicated the possible reversal effect of oxytocin on the adverse effects of EE on the social and anxiety behaviours.
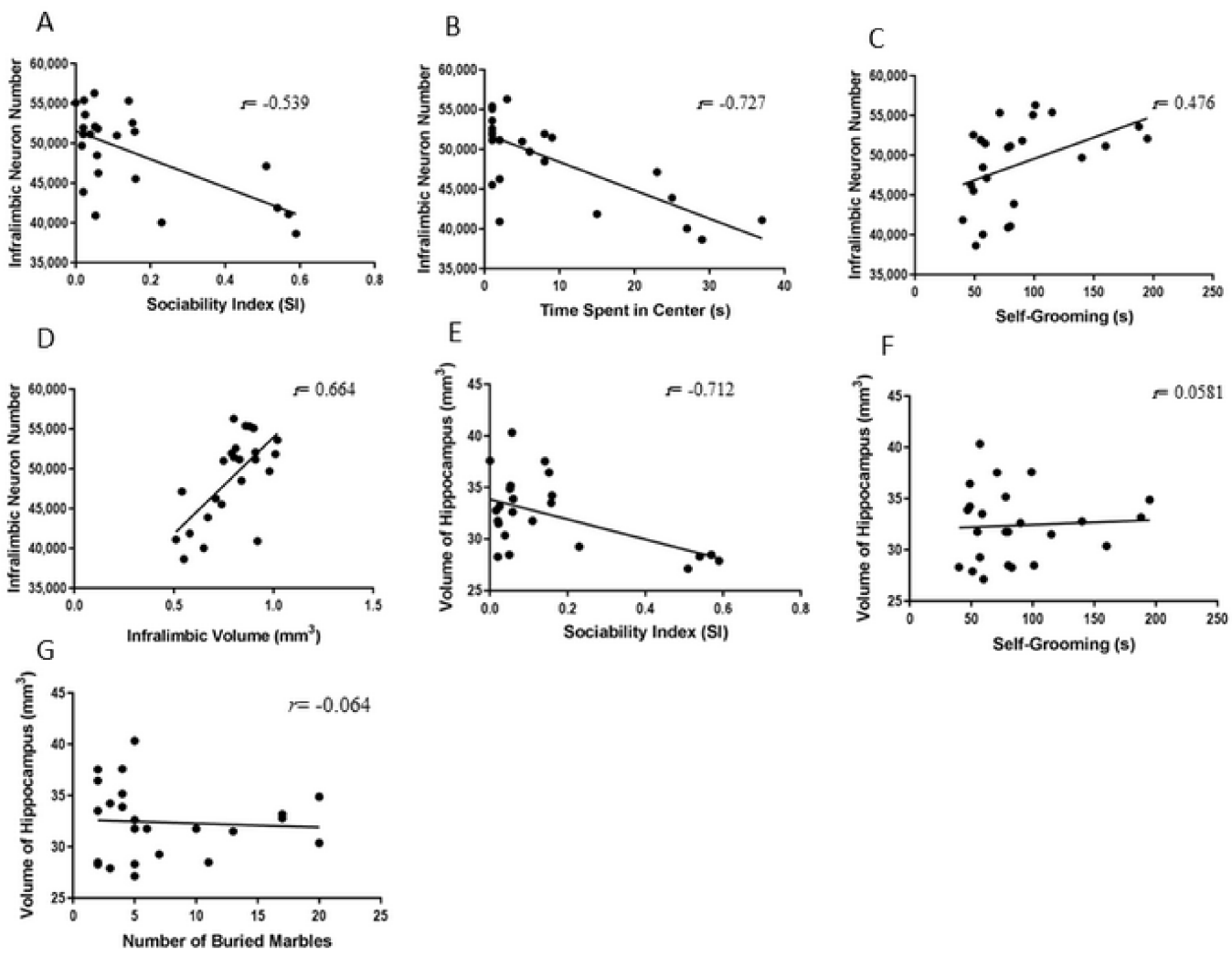

Figure 8. Significant negative correlations between number of the neurons in the infra-limbic area and social index and time spent in centre of the open field $(r=-0.539, p=0.007$ and $r=-0.727, p<0.001)(\mathbf{A}, \mathbf{B})$. Significant positive correlation between neuron number in the infra-limbic and self-grooming $(r=0.476, p=0.019)(\mathbf{C})$ and infra-limbic volume $(r=0.664, p<0.001)$ (D). Significant negative correlation between volume of the hippocampus and sociability index $(r=-0.712, p<0.001)(\mathbf{E})$. No significant correlation between repetitive behaviours (marble burying and self-grooming) and hippocampus volume $(\mathbf{F}, \mathbf{G})$ were observed $(p>0.05)$. 

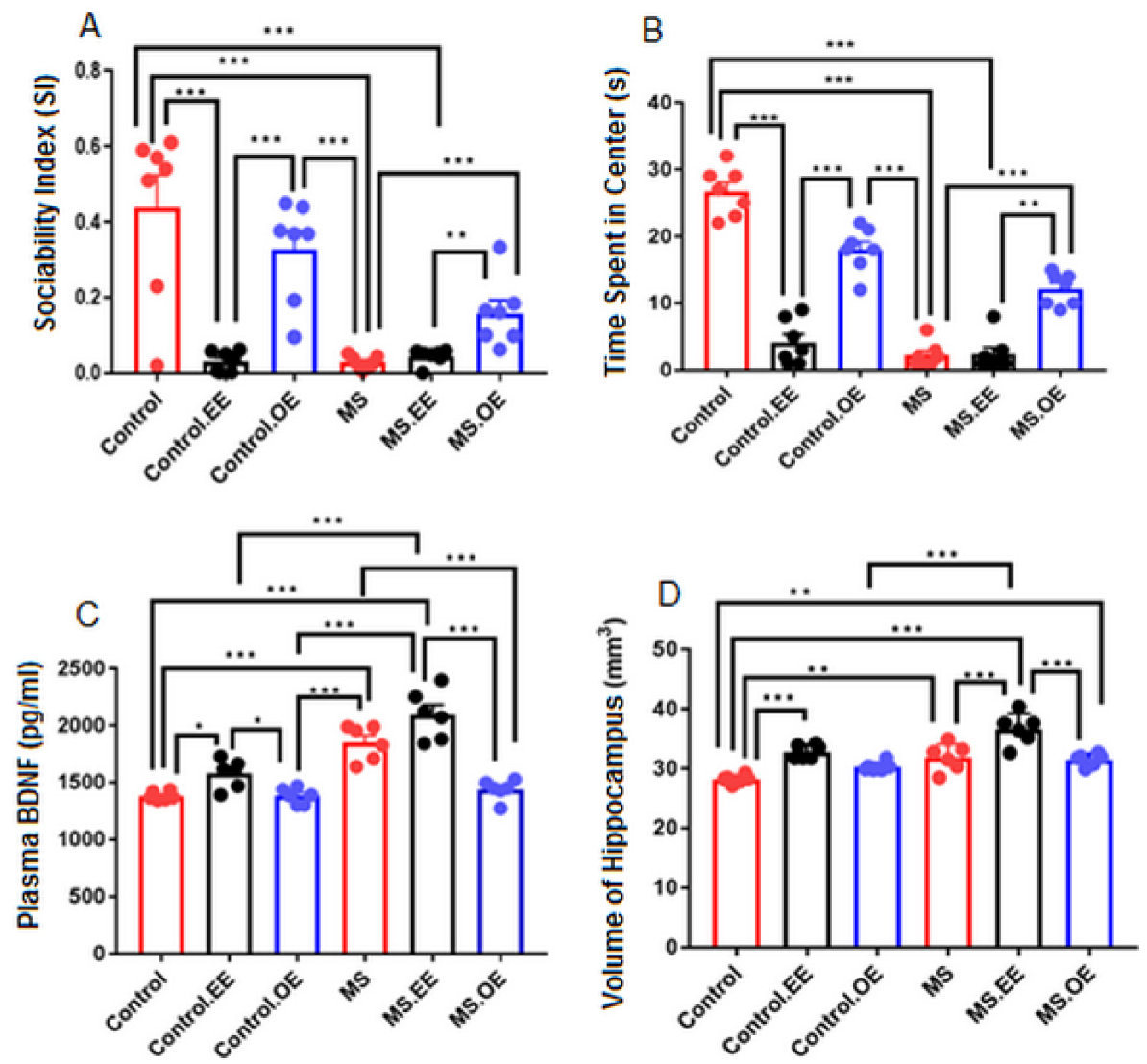

Figure 9. Effects of oxytocin on the negative effects of EE on the social index $(n=10)$ (A), anxiety $(n=10)(\mathbf{B})$, plasma BDNF level $(n=6)(\mathbf{C})$ and volume of the hippocampus $(n=6)(\mathbf{D})$. ${ }^{*} p<0.05,{ }^{* *} p<0.01,{ }^{* * *} p<0.001$. Data for plasma BDNF and hippocampus volume are presented before log-transformation, MS: Maternal Separation, EE: Environmental Enrichment.

\section{Discussion}

The main finding in the present work was that environmental enrichment, applied after weaning, had dual effects on autism-related behaviors in a rat model of maternal separation. EE reduced repetitive behaviors which were induced by maternal separation, but had no effect on anxiety and social behavioral deficits in the maternal separated group. Similarly, in the control group, environmental enrichment resulted in decreased social behaviors and increased anxiety-like behavior. Quantitative analysis of brain demonstrated that enriched environment increased volume of the hippocampus and the infra-limbic area in parallel with increased number of pyramidal neurons and higher plasma BDNF level. We also demonstrated that oxytocin could ameliorate the adverse effects of EE on anxiety and social behaviors and normalized plasma BDNF levels.

These findings are in accordance and extend earlier findings, where environmental factors had a key role in the etiology of autism [26,27]. Early life stress, such as low maternal care in rodents, alters the methylation pattern of involved genes in the stress response cascade, and affects hippocampal development which is associated with increased susceptibility to anxiety and depression-like behaviors $[28,29]$. Studies in rodent offspring found that the mother-pup relationship is crucial for the growth and development of offspring [5]. Indeed, any disruption in this relationship causes disruption in both mother and pup oxytocin systems which finally lead to impaired brain development of the pups [30] and could be one of the mechanisms underlying autism related behavioral following maternal separation. In agreement with our results, the development of autism-like behaviors following adverse early-life experience in rats has been reported in several studies $[11,12,31]$.

We detected alternations in plasma BDNF levels and increased neuroplasticity of the hippocampus and infra-limbic brain regions by maternal separation and EE. It is of interest 
that both MS and EE separately caused an increase in the level of plasma BDNF and the EE effect was further enhanced when combined with MS. Although plasma BDNF level increased in control.EE group compared to the intact control group, there was a significant difference between MS and control.EE groups. On the other hand, there was no significant difference between MS and MS.EE groups. Therefore, MS had a stronger effect on increasing plasma BDNF level than enriching the environment, and this may be one of the reasons for the different behavioral effects of these two factors. Numerous data indicate that BDNF has a critical role in the neuronal plasticity in connection with psychiatric disorders, and changes in the level of neurotrophins following exposure to stressful events in early life, lead to greater sensitivity and vulnerability to mental disorders in adulthood [1,32]. Several studies observed increased levels of BDNF in the plasma of rodents and primates following early life maternal deprivation $[33,34]$. Positive correlation between peripheral (including plasma and blood) and brain BDNF levels have been observed in rats suggesting that plasma BDNF levels may reflect the BDNF expression in the brain [35]. Therefore, our findings on the neuroplasticity changes could be indirectly due to the BDNF level alternations. In our published study, we found the effect of oxytocin on the improvement of the autistic like behaviors and normalizing the plasma BDNF level in the maternal separated rats (24). In the supplementary study of this work we also found that oxytocin can reverse the elevated plasma BDNF level in the EE groups resulting in the improvement of the behavioral phenotypes. This suggests that BDNF may play an important role in the pathophysiological changes underlying autistic-like behaviors. It is of interest that elevated BDNF levels in the plasma of ASD patients has been reported [36]. Importantly a significant correlation between the severe form of autism and higher level of peripheral BDNF level was reported [37]. It is indicated that BDNF is involved in the survival and differentiation of dopaminergic neurons in the developing brain [38]. Recently, it is also shown that enrichment conditions resulted in decrease in the D2 receptor expression in the hippocampus [39]. Accordingly, modulation of dopaminergic neurons by BDNF could be one of the possible explanations of effect of EE on the autistic like behaviors. It is also shown that the variation, $\mathrm{c}$.Val66Met located in the BDNF gene has been associated with increased BDNF serum concentration in depressed patients [40] and c.Val66Met has identified as a possible genetic modifier of disease severity in Rett syndrome [41].

Recently, it is shown that physical enrichment (PE) versus social enrichment (SE) may differentially influence the synaptic plasticity of brain with the consequence of behavioral alteration. In the environmental enrichment paradigm, the animals are kept in a wide interactive environment with a variety of objects in terms of texture, size and shape that are regularly changed [42,43]. Past studies showed that exposure to an enriched environment in wild type animals improved memory, learning, and reduced anxiety [44,45]. For instance, benefits of EE on the improvement of behavioral impairments such as motor performance, depressive-like behavior, as well as defects in BDNF expression in the hippocampus and striatum in mice models of Huntington's disease have been effectively shown [46,47]. In the present study, we observed the effect of EE on reducing repetitive behaviors which were induced by maternal separation [48]. The remarkable note in our results was an increase in anxiety and a decrease in the social behavior in rats experiencing the enriched environment. There are conflicting results regarding the effects of environmental enrichment on the autism symptoms. For example, in 2018 a study on the genetic model of Shank3 autism showed the negative effect of environmental enrichment on the anxiety and its lack of impact on social behavior [22]. In 2012 Lacaria et al. stated that although EE was able to show positive effects on some behaviors in mice, it resulted in increased non-contact violence in the direct and inactive social interaction test in normal mice [23]. In a study on the rats, an increase in basal corticosterone concentration following infra-limbic stimulation happened by environmental enrichment [49]. Accordingly, these evidences would help us explaining the increased number of the neurons in the infra-limbic and bigger size of this area along with higher anxiety behavior in EE groups in the present study. However more detailed studies may help to clarify the detailed mechanistic pathway. Although the 
mechanism of environmental enrichment benefits is not fully understood, it has been suggested that BDNF expression in the hippocampus is enhanced by sustained epigenetic changes of promoters under enriched environment [50] and positive correlation between increased plasma and hippocampus BDNF levels has been seen in rats under the environmental enrichment [51]. Stimulation of BDNF signaling by EE in the hippocampus of mice Alzheimer's disease model has also been observed by up-regulating BDNF mRNA expression level $[52,53]$. It is noteworthy that changes in the BDNF level resulted in increased glutamate receptors expression, including AMPA receptor family, glutamate receptor-1 (GluR1), glutamate receptor-2 (GluR2), and NMDA receptors [54,55]. Considering that changes in the glutamate system is implicated in the disruption of the inhibitory excitatory balance of the brain in autism [11], this might be one possible reason for the adverse effects of EE on social behavior. Interestingly, the suppression of the glutamate system in infra-limbic via reducing the release of glutamate by oxytocin has been demonstrated [56], which gives us the possible explanation for the therapeutic effect of oxytocin on the adverse effects of EE.

We believe that following factors about the behavioral results must be considered: 1 . The time and duration of the environmental enrichment period. In this study, environmental enrichment started from the day of weaning and continued by the day of behavioral testing (PND42-50). Sudden entry into the enriched environment may act as a trigger for stress. It may be possible to get different results by reducing the enrichment duration that could be considered in the future studies; 2 . Over-involvement of animals with objects as a reducing agent of social interaction and that could be an explanation for the decline in social behavior in the EE groups; 3 . Excessive stimulation by changing the objects every five days during EE might cause psychological overloading and in turn behavioral abnormalities; 4. Increasing in the number of animals, even with larger cages, may increase competition by exacerbating violent behaviors associated with increased anxiety and a decreased tendency for social behavior. Despite the general categorization of special environmental conditions as harmful and/or beneficial to health, one of the challenges in psychiatric research is that not all individuals exhibit the same reactions [57]. Therefore, it requires further investigations to find the mechanism of action and define a standard method with precise determination of its various features to the correct and beneficial application.

The complex and rather unknown pathophysiology of ASD is one of the limitations of the related research particularly in animal models. Difference in the environmental enrichment in laboratories such as size of the cage, number of the animals, playing equipment, frequency of object changing are other limitations of the current work which make the direct comparisons and conclusion complex.

\section{Material and Methods}

\subsection{Animals and Maternal Separation}

Animals were kept at $21{ }^{\circ} \mathrm{C}$, humidity (50\%) and 12/12 light-dark cycle (lights on at 7:00 a.m.) with free access to food (Pellets, Pars Animal Feed Co., Iran) and water during the experiment. Male and female wistar rats (260-290 $\mathrm{g}$ and 10-11-week old, $n=10$ in each group) were purchased from School of Biology, Shahid Beheshti University (Iran), and used for mating. The animals were housed in cages $\left(26.5 \times 42 \times 15 \mathrm{~cm}^{3}\right.$ in size and $n=4-5$ per cage) and allowed to acclimatize in the animal colony for two weeks before any procedures commenced. Male and female rats were randomly paired during 5 days in the cages in the size of $26.5 \times 42 \times 15 \mathrm{~cm}^{3}$ allowing them to mate. Nine pregnant rats were kept individually in the same size of cages for one week before giving birth (Gestational day (GD) 14-21). Subsequently, male pups $(n=40)$ from 75 litters were randomly divided into two groups: maternal separation (MS) and control. In the maternal separation group, pups were separated from their mother for $3 \mathrm{~h}$ (9-12 a.m.) at PND (post-natal day) 1-14, placed individually in small cages $\left(24 \times 13.5 \times 13 \mathrm{~cm}^{3}\right.$; about $4 \mathrm{~m}$ far from the mother). From PND15-21, the rats remained with their mothers. The pups in the control group were normally raised with the mother until weaning age. At PND21, the rats of both 
groups were equally divided into two subgroups of either environmental enrichment (EE) or normal conditions. Accordingly, the study consisted of 4 groups (10 rats in each group) as follows: Control; control.EE; MS; MS.EE.

This research was conducted in accordance with Ethics Committee standards of Shahid Beheshti University (IR.SBU.ICBS.97.1045).

\subsection{Environmental Enrichment}

Two groups of animals were randomly selected among the pups (control.EE and MS.EE) and underwent environmental enrichment after weaning (PND21). The rats were housed in large cages $\left(50 \times 80 \times 30 \mathrm{~cm}^{3}\right)$ with a greater number of rats $(n=8-9)$ in each cage, and provided with different objects and playing equipment (Figure 10). These objects were changed every 5 days until the behavioral test day. The other two groups without treatment (control and MS) were kept under the normal housing conditions (cages with $26.5 \times 42 \times 15 \mathrm{~cm}^{3}$ in size and $n=4$ in each cage) with no enrichment of environment.

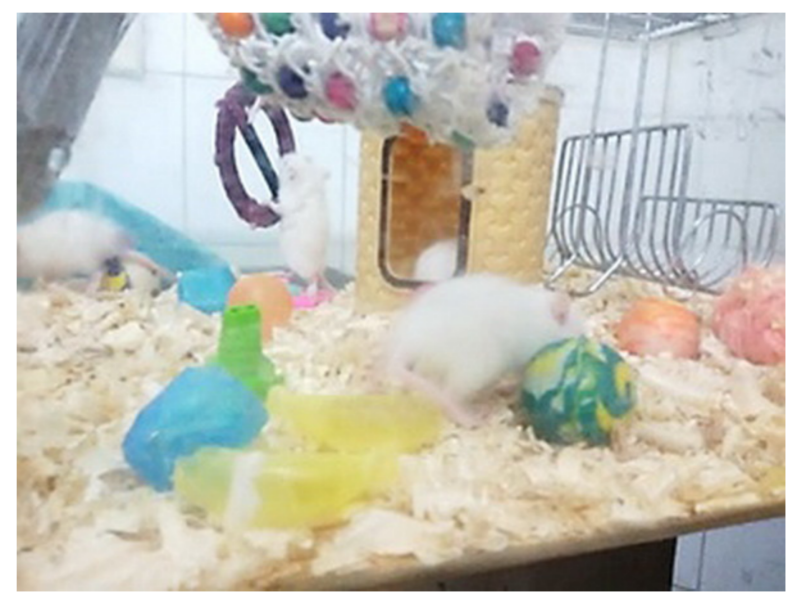

Figure 10. Example of environmental enrichment: after weaning at PND21, rats were kept in large cages with a greater number of rats, different objects and playing equipment which were changed every 5 days, until the behavioral test day.

\subsection{Supplementary Experiment}

After completing the experiments and considering the results given below, as well as the results of previous work in which we showed the effect of oxytocin in improving autism-related symptoms, we decided to investigate the combined effect of oxytocin and environmental enrichment (OE) on some parameters which were altered unexpectedly following EE. For this purpose, two other groups of rats (control.OE and MS.OE) were defined, which received both oxytocin and EE treatments. Oxytocin (O3251Sigma) was administered intraperitoneally (ip) in a dose of $1 \mathrm{mg} / \mathrm{kg}$ from PND22 to PND30 (with $48 \mathrm{~h}$ interval) and EE was applied as described above.

\subsection{Behavioral Tests}

At adolescence (PND42-50), sociability, repetitive, anxiety-like behaviors, and motor activity were assessed using the three-chamber, marble burying, and open-field tests, respectively. The rats were transferred to the behavioral test room one hour before starting the tests, and all tests were performed in a dimly lit room (20 lux) during one day ( 8 a.m. 3 p.m.) in the following order to decrease the amount of stress: (1) Three-chamber test; (2) Open field test, and (3) Marble burying test. The test boxes were cleaned with 70\% alcohol between each test. Each day, four rats were tested, with all tests recorded with cameras on top of the boxes ( $80 \mathrm{~cm}$ above the floor). Details of the behavioral tests have been described previously [24]. 


\subsubsection{Three-Chamber Test}

Briefly, the three-chamber test is used for examining the social behavior in rodents [58]. The test rat was placed for $5 \mathrm{~min}$ in the middle chamber of a three-chamber box $\left(20 \times 35 \times 40 \mathrm{~cm}^{3}\right.$ for each chamber) with the chambers connected to each other with glass walls. Thereafter, the rat freely moved and habituated to the all chambers for $10 \mathrm{~min}$. Subsequently, a stranger rat of the same age and sex with no previous contact with the test rat was placed in one of the side chambers, and in the other side of the chamber, an empty cage was placed as a novel object. Finally, the doors were simultaneously opened, and the test rat had $10 \mathrm{~min}$ to freely move between the three chambers. At the end of the test, the rat was transferred to the resting cage and was given an hour before going through the next test. The following parameters were recorded in the three-chamber test: time spent in the stranger rat chamber, time spent in the novel object chamber, time spent sniffing stranger rat, and time spent sniffing novel object. The criterion for sniffing time was the nose directly toward the stranger rat or empty cage.

\subsubsection{Open Field Test}

In the open-field test, the rat was placed for $15 \mathrm{~min}$ in a box $\left(40 \times 40 \times 40 \mathrm{~cm}^{3}\right)$ which was divided by lines into the central circle and squares around it [11]. The following parameters were recorded in this test: time spent in the central circle, time spent for selfgrooming, number of times the rat crossed the lines. The rats were then returned to the resting cage and marble burying test was performed after an hour of resting.

\subsubsection{Marble Burying Test}

This test was performed for $30 \mathrm{~min}$ in a $\left(40 \times 40 \times 40 \mathrm{~cm}^{3}\right)$ box with 20 glass marbles arranged in 5 rows. After $30 \mathrm{~min}$ of test, the number of hidden marbles $(75 \%$ covered with bedding) was considered as the stereotype behavior [59].

\subsubsection{Tissue Preparation}

Thirty minutes after completing behavioral tests, the rats were deeply anesthetized with ketamine (Ratiopharm, Germany; $150 \mathrm{mg} / \mathrm{kg}$, i.p) and blood samples were taken directly from heart using EDTA-covered tubes. The blood samples were centrifuged at $6000 \mathrm{rpm}$ for $20 \mathrm{~min}$ and the supernatants were stored at $-80^{\circ} \mathrm{C}$ until further processing. Subsequently, transcardial perfusion was performed with ice cold saline followed by $4 \%$ paraformaldehyde in $0.1 \mathrm{M}$ phosphate buffer (PB, $\mathrm{pH} 7.4$ ) for $10 \mathrm{~min}$. The brains were then extracted and stored in the same fixative solution at $4{ }^{\circ} \mathrm{C}$ until further processing. At the time of tissue analysis, right or left hemispheres of the brains were randomly selected and kept in 30\% sucrose for $72 \mathrm{~h}$, then frozen in liquid nitrogen and coronally cut at 50- $\mu \mathrm{m}$ thickness on cryostat cutting devise (SCILab, Cool-Cut, SCI85683, England). Using a systematic sampling principle, the systematic sampling fraction (SSF) for hippocampus and medial prefrontal cortex were $1 / 12$ and $1 / 3$, respectively. The first section of each region was selected using a random number table. One series of brain sections was Nissl stained with $0.25 \%$ thionin (Sigma T3387).

\subsubsection{Plasma BDNF Level Assay}

Plasma BDNF level was assessed according to the manufacturer's description. Briefly, using ELISA kits (Sigma RAB 1138), the plasma samples were diluted and applied in 1:300 with the standard curve in the range of $12-3000 \mathrm{pg} . / \mathrm{mL}$. The reaction rate was measured at $450 \mathrm{~nm}$ using a microplate reader (Biotech, Oklahoma City, OK, USA, 100 Tigan St, Winooski, VT 05404, USA).

\subsection{Three-D Quantitative Measurements of the Brain Volume Estimation}

Volume of the hippocampus and its sub-regions including granular cell layer $(\mathrm{GCl})$, molecular layer of dentate gyrus (MDG) and CA1 stratum radiatum (CA1.SR), and infra- 
limbic and pre-limbic areas of the MPFC were measured using the Cavalieri estimator with point counting, and the newCAST software (Visiopharm, Hørsholm, Denmark) and light microscope (Olympus, BX56) modified for stereology with motorized stage (H1P4BX ProScan stage with V31XYZE ProScan III Controller). Delineation of area of interest was performed using an objective lens $4 \times$ and the volume measurement was done using an objective lens $10 \times$. To calculate the volume of brain regions following formula was used [60,61]:

$$
V=\sum P \cdot\left(\frac{a}{p}\right) \cdot T \cdot \frac{1}{S S F}
$$

where $\sum P$ was the total number of the points counted in the delineated regions per animal, $(a / p)$ was the area per test point; $T$ is the section thickness $(50-\mu \mathrm{m})$, and SSF was the section sampling fraction (1/12 for hippocampus and subregions and $1 / 3$ for $\mathrm{mPFC}$ subregions).

\subsection{Estimation of the Pyramidal Neuron Number}

The optical fractionator method was applied by using $60 \times$ oil-immersed objective lens in order to count the number of pyramidal neurons in the infralimbic area. The effect of section shrinkage during tissue preparation was corrected based on the optimal disector height determination by counting the number of neurons through the full thickness of nine brain sections from the infralimbic area (with systematic random sampling the sections between animals). In the thickness from $5-\mu \mathrm{m}$ to $15-\mu \mathrm{m}$ (10- $\mu \mathrm{m}$ thickness) a constant cell density was seen using Z-plot (histogram) of the counted neurons. The criterion for counting the pyramidal neurons was the nucleolus being in focus and fully or partially inside the unbiased counting frame without touching the forbidden lines. The following formula was used to calculate the total number of pyramidal neurons:

$$
N=\frac{1}{S S F} \cdot \frac{1}{A S F} \cdot \frac{1}{H S F} \cdot \sum Q-
$$

where $N$ was the total number of pyramidal neurons in infralimbic area; $\Sigma Q-$ was the number of the counted pyramidal neurons; SSF was the section sampling fraction (1/3); $A S F$ was an area sampling fraction; and HSF was the height sampling fraction (mean of the $Q$ - weighted height of the dissector) [62].

\subsection{Statistical Analysis}

Statistical analysis was performed using SPSS software (IBM SPSS Statistics for Windows, Version 24.0. Armonk, NY: IBM Corp) and plots were generated using GraphPad Prism version 8 (GraphPad software, San Diego, CA, USA). A Q-Q plot was generated to check the normality of data distribution. Equality of variances was assessed by Leven's test. In case of inequality of variances, logarithmic transformation was performed on the original data. Within group comparison was performed for social behaviors by repeatedmeasures analysis of variance (ANOVA) [24]. Other data were analyzed using two-way ANOVA followed by Tukey post-hoc test. Two tailed Pearson analysis was used to find the correlation between variables. Data were presented as mean \pm SEM. The null hypothesis was rejected with $p<0.05$ as the level of significance.

\section{Conclusions}

The current study indicates that environmental enrichment ameliorates repetitive behaviors in a maternal separation rat model of autism but caused increased anxiety and social behaviors deficits alongside with elevated plasma BDNF levels which was associated with plasticity changes in the hippocampus and infra-limbic cortical area. BDNF can be highlighted as a mediator of effects of EE on social and anxiety behaviors as well as brain plasticity changes. It seems that changes in the plasma BDNF level had no relation with repetitive behaviors indicating the different involved mechanism in repetitive behavior than the mechanisms underlying social behavioral deficits in ASD which requires further studies to achieve certainty. Taken together, our results suggest that therapeutic approach 
of environmental enrichment still needs more investigations to find the answer to the open questions on some negative effects.

Author Contributions: All authors have contributed substantially to the work reported. All authors have read and agreed to the published version of the manuscript.

Funding: This research is supported by HKH Kronprinsessan Lovisas Förening för barnasjukvård/Stifelsen Axel Tielmans Minnesfond 2020-00559.

Institutional Review Board Statement: The study was conducted according to the guidelines of the Ethics Committee standards of Shahid Beheshti University and approved by the Institutional Review Board of Shahid Beheshti University (IR.SBU.ICBS.97.1045).

Informed Consent Statement: Not applicable.

Data Availability Statement: The data presented in this study are available on request from the corresponding author. The data are not publicly available due tosome further analysis might be done to publish another paper from the data.

Acknowledgments: We would like to show our gratitude to the Soltani family that financially supported this research.

Conflicts of Interest: The authors declare no conflict of interest.

\section{References}

1. Cirulli, F. Role of environmental factors on brain development and nerve growth factor expression. Physiol. Behav. 2001, 73, 321-330. [CrossRef]

2. Hair, N.L.; Hanson, J.L.; Wolfe, B.L.; Pollak, S.D. Association of Child Poverty, Brain Development, and Academic Achievement. JAMA Pediatrics 2015, 169, 822-829. [CrossRef] [PubMed]

3. Carr, C.P.; Martins, C.M.; Stingel, A.M.; Lemgruber, V.B.; Juruena, M.F. The role of early life stress in adult psychiatric disorders: A systematic review according to childhood trauma subtypes. J. Nerv. Ment. Dis. 2013, 201, 1007-1020. [CrossRef] [PubMed]

4. Loman, M.M.; Gunnar, M.R. Early experience and the development of stress reactivity and regulation in children. Neurosci. Biobehav. Rev. 2010, 34, 867-876. [CrossRef] [PubMed]

5. Levine, S. Infantile experience and resistance to physiological stress. Science 1957, 126, 405. [CrossRef] [PubMed]

6. Luo, W.; Zhang, C.; Jiang, Y.H.; Brouwer, C.R. Systematic reconstruction of autism biology from massive genetic mutation profiles. Sci. Adv. 2018, 4, e1701799. [CrossRef]

7. Kleijer, K.T.E.; Huguet, G.; Tastet, J.; Bourgeron, T.; Burbach, J.P.H. Anatomy and Cell Biology of Autism Spectrum Disorder: Lessons from Human Genetics. Adv. Anat. Embryol. Cell Biol. 2017, 224, 1-25. [CrossRef]

8. Steffenburg, S.; Gillberg, C.; Hellgren, L.; Andersson, L.; Gillberg, I.C.; Jakobsson, G.; Bohman, M. A twin study of autism in Denmark, Finland, Iceland, Norway and Sweden. J. Child Psychol. PsychiatryAllied Discip. 1989, 30, 405-416. [CrossRef]

9. Hallmayer, J.; Cleveland, S.; Torres, A.; Phillips, J.; Cohen, B.; Torigoe, T.; Miller, J.; Fedele, A.; Collins, J.; Smith, K.; et al. Genetic heritability and shared environmental factors among twin pairs with autism. Arch. Gen. Psychiatry 2011, 68, 1095-1102. [CrossRef]

10. Sadeghi, S.; Pouretemad, H.; Khosrowabadi, R.; Fathabadi, J.; Nikbakht, S. Behavioral and electrophysiological evidence for parent training in young children with autism symptoms and excessive screen-time. Asian J. Psychiatry 2019, 45, 7-12. [CrossRef]

11. Sayed Javad Javaheri, E.S.; Bigdeli, M.R.; Zibaii, M.I.; Dargahi, L.; Pouretemad, H.R. Optogenetic Stimulation of the Anterior Cingulate Cortex Ameliorates Autistic-Like Behaviors in Rats Induced by Neonatal Isolation, Caudate Putamen as a Site for Alteration. Neuromolecular Med. 2019, 21, 132-142. [CrossRef] [PubMed]

12. Tan, T.; Wang, W.; Xu, H.; Huang, Z.; Wang, Y.T.; Dong, Z. Low-Frequency rTMS Ameliorates Autistic-Like Behaviors in Rats Induced by Neonatal Isolation Through Regulating the Synaptic GABA Transmission. Front. Cell. Neurosci. 2018, 12, 46. [CrossRef] [PubMed]

13. Lyall, K.; Schmidt, R.J.; Hertz-Picciotto, I. Maternal lifestyle and environmental risk factors for autism spectrum disorders. Int. J. Epidemiol. 2014, 43, 443-464. [CrossRef] [PubMed]

14. Meaney, M.J.; Mitchell, J.B.; Aitken, D.H.; Bhatnagar, S.; Bodnoff, S.R.; Iny, L.J.; Sarrieau, A. The effects of neonatal handling on the development of the adrenocortical response to stress: Implications for neuropathology and cognitive deficits in later life. Psychoneuroendocrinology 1991, 16, 85-103. [CrossRef]

15. Dawson, G. Early behavioral intervention, brain plasticity, and the prevention of Autism Spectrum Disorder. Dev. Psychopathol. 2008, 20, 775-803. [CrossRef]

16. Hannan, A.J. Environmental enrichment and brain repair: Harnessing the therapeutic effects of cognitive stimulation and physical activity to enhance experience-dependent plasticity. Neuropathol. Appl. Neurobiol. 2014, 40, 13-25. [CrossRef]

17. Garbugino, L.; Centofante, E.; D'Amato, F.R. Early Social Enrichment Improves Social Motivation and Skills in a Monogenic Mouse Model of Autism, the Oprm1 (-/-) Mouse. Neural Plast. 2016, 2016, 5346161. [CrossRef] 
18. Kerr, B.; Silva, P.A.; Walz, K.; Young, J.I. Unconventional transcriptional response to environmental enrichment in a mouse model of Rett syndrome. PloS ONE 2010, 5, e11534. [CrossRef]

19. Reynolds, S.; Urruela, M.; Devine, D.P. Effects of environmental enrichment on repetitive behaviors in the BTBR T+tf/J mouse model of autism. Autism Res. Off. J. Int. Soc. Autism Res. 2013, 6, 337-343. [CrossRef]

20. Yamaguchi, H.; Hara, Y.; Ago, Y.; Takano, E.; Hasebe, S.; Nakazawa, T.; Hashimoto, H.; Matsuda, T.; Takuma, K. Environmental enrichment attenuates behavioral abnormalities in valproic acid-exposed autism model mice. Behav. Brain Res. 2017, $333,67-73$. [CrossRef]

21. Favre, M.R.; La Mendola, D.; Meystre, J.; Christodoulou, D.; Cochrane, M.J.; Markram, H.; Markram, K. Predictable enriched environment prevents development of hyper-emotionality in the VPA rat model of autism. Front. Neurosci. 2015, 9, 127. [CrossRef] [PubMed]

22. Hulbert, S.W.; Bey, A.L.; Jiang, Y.H. Environmental enrichment has minimal effects on behavior in the Shank3 complete knockout model of autism spectrum disorder. Brain Behav. 2018, 8, e01107. [CrossRef] [PubMed]

23. Lacaria, M.; Spencer, C.; Gu, W.; Paylor, R.; Lupski, J.R. Enriched rearing improves behavioral responses of an animal model for CNV-based autistic-like traits. Hum. Mol. Genet. 2012, 21, 3083-3096. [CrossRef] [PubMed]

24. Mansouri, M.; Pouretemad, H.; Roghani, M.; Wegener, G.; Ardalan, M. Autistic-like behaviours and associated brain structural plasticity are modulated by oxytocin in maternally separated rats. Behav. Brain Res. 2020, 393, 112756. [CrossRef] [PubMed]

25. Businaro, R.; Corsi, M.; Azzara, G.; Di Raimo, T.; Laviola, G.; Romano, E.; Ricci, L.; Maccarrone, M.; Aronica, E.; Fuso, A.; et al. Interleukin-18 modulation in autism spectrum disorders. J. Neuroinflammation 2016, 13, 2. [CrossRef]

26. Meng, F.T.; Zhao, J.; Ni, R.J.; Fang, H.; Zhang, L.F.; Zhang, Z.; Liu, Y.J. Beneficial effects of enriched environment on behaviors were correlated with decreased estrogen and increased BDNF in the hippocampus of male mice. Neuro Endocrinol. Lett. 2015, 36, 490-497.

27. Caldeira, M.V.; Melo, C.V.; Pereira, D.B.; Carvalho, R.F.; Carvalho, A.L.; Duarte, C.B. BDNF regulates the expression and traffic of NMDA receptors in cultured hippocampal neurons. Mol. Cell. Neurosci. 2007, 35, 208-219. [CrossRef]

28. Caldeira, M.V.; Melo, C.V.; Pereira, D.B.; Carvalho, R.; Correia, S.S.; Backos, D.S.; Carvalho, A.L.; Esteban, J.A.; Duarte, C.B. Brain-derived neurotrophic factor regulates the expression and synaptic delivery of alpha-amino-3-hydroxy-5-methyl-4-isoxazole propionic acid receptor subunits in hippocampal neurons. J. Biol. Chem. 2007, 282, 12619-12628. [CrossRef]

29. Ninan, I. Oxytocin suppresses basal glutamatergic transmission but facilitates activity-dependent synaptic potentiation in the medial prefrontal cortex. J. Neurochem. 2011, 119, 324-331. [CrossRef]

30. Niwa, M.; Jaaro-Peled, H.; Tankou, S.; Seshadri, S.; Hikida, T.; Matsumoto, Y.; Cascella, N.G.; Kano, S.; Ozaki, N.; Nabeshima, T.; et al. Adolescent stress-induced epigenetic control of dopaminergic neurons via glucocorticoids. Science 2013, 339, 335-339. [CrossRef]

31. Crawley, J.N. Designing mouse behavioral tasks relevant to autistic-like behaviors. Ment. Retard. Dev. Disabil. Res. Rev. 2004, 10, 248-258. [CrossRef] [PubMed]

32. Pasciuto, E.; Borrie, S.C.; Kanellopoulos, A.K.; Santos, A.R.; Cappuyns, E.; D'Andrea, L.; Pacini, L.; Bagni, C. Autism Spectrum Disorders: Translating human deficits into mouse behavior. Neurobiol. Learn. Mem. 2015, 124, 71-87. [CrossRef] [PubMed]

33. Ardalan, M.; Rafati, A.H.; Nyengaard, J.R.; Wegener, G. Rapid antidepressant effect of ketamine correlates with astroglial plasticity in the hippocampus. Br. J. Pharm. 2017, 174, 483-492. [CrossRef] [PubMed]

34. Anzabi, M.; Ardalan, M.; Iversen, N.K.; Rafati, A.H.; Hansen, B.; Ostergaard, L. Hippocampal Atrophy Following Subarachnoid Hemorrhage Correlates with Disruption of Astrocyte Morphology and Capillary Coverage by AQP4. Front. Cell Neurosci. 2018, 12, 19. [CrossRef] [PubMed]

35. Ardalan, M.; Wegener, G.; Polsinelli, B.; Madsen, T.M.; Nyengaard, J.R. Neurovascular plasticity of the hippocampus one week after a single dose of ketamine in genetic rat model of depression. Hippocampus 2016, 26, 1414-1423. [CrossRef]

36. Christensen, J.; Gronborg, T.K.; Sorensen, M.J.; Schendel, D.; Parner, E.T.; Pedersen, L.H.; Vestergaard, M. Prenatal valproate exposure and risk of autism spectrum disorders and childhood autism. JAMA 2013, 309, 1696-1703. [CrossRef]

37. Kirsten, T.B.; Chaves-Kirsten, G.P.; Chaible, L.M.; Silva, A.C.; Martins, D.O.; Britto, L.R.; Dagli, M.L.; Torrao, A.S.; Palermo-Neto, J.; Bernardi, M.M. Hypoactivity of the central dopaminergic system and autistic-like behavior induced by a single early prenatal exposure to lipopolysaccharide. J. Neurosci. Res. 2012, 90, 1903-1912. [CrossRef]

38. Meaney, M.J.; Szyf, M. Maternal care as a model for experience-dependent chromatin plasticity? Trends Neurosci. 2005, 28, 456-463. [CrossRef]

39. Weaver, I.C.; Champagne, F.A.; Brown, S.E.; Dymov, S.; Sharma, S.; Meaney, M.J.; Szyf, M. Reversal of maternal programming of stress responses in adult offspring through methyl supplementation: Altering epigenetic marking later in life. J. Neurosci. Off. J. Soc. Neurosci. 2005, 25, 11045-11054. [CrossRef]

40. Nagasawa, M.; Okabe, S.; Mogi, K.; Kikusui, T. Oxytocin and mutual communication in mother-infant bonding. Front. Hum. Neurosci. 2012, 6, 31. [CrossRef]

41. Wu, X.; Bai, Y.; Tan, T.; Li, H.; Xia, S.; Chang, X.; Zhou, Z.; Zhou, W.; Li, T.; Wang, Y.T.; et al. Lithium ameliorates autistic-like behaviors induced by neonatal isolation in rats. Front. Behav. Neurosci. 2014, 8, 234. [CrossRef] [PubMed]

42. Alleva, E.; Francia, N. Psychiatric vulnerability: Suggestions from animal models and role of neurotrophins. Neurosci. Biobehav. Rev. 2009, 33, 525-536. [CrossRef] [PubMed] 
43. Cirulli, F.; Francia, N.; Branchi, I.; Antonucci, M.T.; Aloe, L.; Suomi, S.J.; Alleva, E. Changes in plasma levels of BDNF and NGF reveal a gender-selective vulnerability to early adversity in rhesus macaques. Psychoneuroendocrinology 2009, 34, 172-180. [CrossRef] [PubMed]

44. Cirulli, F.; Francia, N.; Berry, A.; Aloe, L.; Alleva, E.; Suomi, S.J. Early life stress as a risk factor for mental health: Role of neurotrophins from rodents to non-human primates. Neurosci. Biobehav. Rev. 2009, 33, 573-585. [CrossRef] [PubMed]

45. Klein, A.B.; Williamson, R.; Santini, M.A.; Clemmensen, C.; Ettrup, A.; Rios, M.; Knudsen, G.M.; Aznar, S. Blood BDNF concentrations reflect brain-tissue BDNF levels across species. Int. J. Neuropsychopharmacol. 2011, 14, 347-353. [CrossRef] [PubMed]

46. Qin, X.-Y.; Feng, J.-C.; Cao, C.; Wu, H.-T.; Loh, Y.P.; Cheng, Y. Association of Peripheral Blood Levels of Brain-Derived Neurotrophic Factor With Autism Spectrum Disorder in Children: A Systematic Review and Meta-analysis. JAMA Pediatrics 2016, 170, 1079-1086. [CrossRef]

47. Enstrom, A.M.; Lit, L.; Onore, C.E.; Gregg, J.P.; Hansen, R.L.; Pessah, I.N.; Hertz-Picciotto, I.; Van de Water, J.A.; Sharp, F.R.; Ashwood, P. Altered gene expression and function of peripheral blood natural killer cells in children with autism. Brain Behav. Immun. 2009, 23, 124-133. [CrossRef]

48. Binder, D.K.; Scharfman, H.E. Brain-derived neurotrophic factor. Growth Factors 2004, 22, 123-131. [CrossRef]

49. Gabriel, P.; Mastracchio, T.A.; Bordner, K.; Jeffrey, R. Impact of enriched environment during adolescence on adult social behavior, hippocampal synaptic density and dopamine D2 receptor expression in rats. Physiol. Behav. 2020, 226, 113133. [CrossRef]

50. Moreira, F.P.; Fabiao, J.D.; Bittencourt, G.; Wiener, C.D.; Jansen, K.; Oses, J.P.; Quevedo Lde, A.; Souza, L.D.; Crispim, D.; Portela, L.V.; et al. The Met allele of BDNF Val66Met polymorphism is associated with increased BDNF levels in generalized anxiety disorder. Psychiatr. Genet. 2015, 25, 201-207. [CrossRef]

51. Zeev, B.; Vecsler, M. The common BDNF polymorphism may be a modifier of disease severity in Rett syndrome (vol 72, pg 1242 , 2009). Neurology 2009, 73, 161. [CrossRef]

52. Nithianantharajah, J.; Hannan, A.J. Enriched environments, experience-dependent plasticity and disorders of the nervous system. Nat. Rev.. Neurosci. 2006, 7, 697-709. [CrossRef] [PubMed]

53. Olsson, I.A.; Dahlborn, K. Improving housing conditions for laboratory mice: A review of "environmental enrichment". Lab. Anim. 2002, 36, 243-270. [CrossRef] [PubMed]

54. Duffy, S.N.; Craddock, K.J.; Abel, T.; Nguyen, P.V. Environmental enrichment modifies the PKA-dependence of hippocampal LTP and improves hippocampus-dependent memory. Learn. Mem. (Cold Spring Harb. N.Y.) 2001, 8, 26-34. [CrossRef] [PubMed]

55. Fox, C.; Merali, Z.; Harrison, C. Therapeutic and protective effect of environmental enrichment against psychogenic and neurogenic stress. Behav. Brain Res. 2006, 175, 1-8. [CrossRef] [PubMed]

56. Nithianantharajah, J.; Barkus, C.; Murphy, M.; Hannan, A.J. Gene-environment interactions modulating cognitive function and molecular correlates of synaptic plasticity in Huntington's disease transgenic mice. Neurobiol. Dis. 2008, 29, 490-504. [CrossRef] [PubMed]

57. Pang, T.Y.; Du, X.; Zajac, M.S.; Howard, M.L.; Hannan, A.J. Altered serotonin receptor expression is associated with depressionrelated behavior in the R6/1 transgenic mouse model of Huntington's disease. Hum. Mol. Genet. 2009, 18, 753-766. [CrossRef]

58. Bechard, A.R.; Cacodcar, N.; King, M.A.; Lewis, M.H. How does environmental enrichment reduce repetitive motor behaviors? Neuronal activation and dendritic morphology in the indirect basal ganglia pathway of a mouse model. Behav. Brain Res. 2016, 299, 122-131. [CrossRef]

59. Ronzoni, G.; Antón, M.; Mora, F.; Segovia, G.; Del Arco, A. Infralimbic cortex controls the activity of the hypothalamus-pituitaryadrenal axis and the formation of aversive memory: Effects of environmental enrichment. Behav. Brain Res. Sreetestcontent1 2016, 297, 338-344. [CrossRef]

60. Zajac, M.S.; Pang, T.Y.; Wong, N.; Weinrich, B.; Leang, L.S.; Craig, J.M.; Saffery, R.; Hannan, A.J. Wheel running and environmental enrichment differentially modify exon-specific BDNF expression in the hippocampus of wild-type and pre-motor symptomatic male and female Huntington's disease mice. Hippocampus 2010, 20, 621-636. [CrossRef]

61. Prasetyo, S.; Yolanda, S.; Ivanali, K. Effect of continuous environmental enrichment and aerobic exercise on rat plasma and hippocampal brain-derived neurotrophic factor. J. Nat. Sci. Biol. Med. 2019, 10, 20-23. [CrossRef]

62. Hu, Y.S.; Long, N.; Pigino, G.; Brady, S.T.; Lazarov, O. Molecular mechanisms of environmental enrichment: Impairments in Akt/GSK3beta, neurotrophin-3 and CREB signaling. PloS ONE 2013, 8, e64460. [CrossRef] [PubMed] 